\title{
Axillary vein thrombosis in adolescent onset systemic sclerosis
}

\author{
Alison Leak, K J Patel, E G D Tuddenham, J D Pearson, Patricia Woo
}

\begin{abstract}
A 16 year old girl with a two year history of systemic sclerosis developed left axillary vein thrombosis. Prolonged euglobulin clot lysis time, anti-endothelial cell antibodies, and raised von Willebrand factor antigen were shown.
\end{abstract}

Progressive systemic sclerosis, an uncommon condition in adults and even rarer in children, ${ }^{1}$ : is characterised by widespread fibrosis thought to be due to microvascular and arteriolar injury. Endothelial cell dysfunction and intravascular factors leading to a procoagulant environment are present, ${ }^{3}$ but thrombosis of large vessels is not a recognised complication of this disease.

We report a teenage girl with systemic sclerosis who developed axillary vein thrombosis and in whom abnormal fibrinolysis and antiendothelial cell antibodies were detected.

\section{Case report}

A 14 year old schoolgirl developed Raynaud's phenomenon and puffy hands in 1985. Examination showed sclerodactyly, articular swelling involving metacarpophalangeal and proximal interphalangeal joints, reduced mouth opening, and grade $3 / 5$ proximal muscle weakness.

Laboratory investigations showed haemoglobin $117 \mathrm{~g} / \mathrm{l}$, erythrocyte sedimentation rate $4 \mathrm{~mm} / \mathrm{h}$, and creatinine kinase $923 \mathrm{IU} / \mathrm{l}$ (normal $<175$ ). During three years of follow up she has had intermittent low titre antinuclear antibody, but no anti-DNA, anti-RNP, or other precipitating antibodies. A muscle biopsy showed inflammatory myositis, which responded to prednisolone $20 \mathrm{mg}$ on alternate days. Progressive dysphagia complicated by ulcerative oesophagitis and deterioration of pulmonary function has occurred, though renal function remains normal.

In April 1988 she reported sudden onset of dilated veins over the left anterior chest wall, followed by gradual swelling of the left arm. There was no history of trauma, strenuous exercise, or superficial thrombophlebitis nor previous history of deep vein thrombosis. She was treated with prednisolone $20 \mathrm{mg}$ on alternate days, ranitidine $150 \mathrm{mg}$ twice daily, and an antacid (Gaviscon) as required. She had never used the contraceptive pill or other hormonal preparations.

Examination showed the characteristic facial appearance of systemic sclerosis with a waxy skin, $4 \mathrm{~cm}$ mouth opening, and puffy hands with terminal sclerodactyly. All other systems were normal except for the left anterior chest wall and arm where there were numerous dilated veins (fig l) and the left arm circumference was larger than the right by $1.5 \mathrm{~cm}$ (measured $15 \mathrm{~cm}$ above the olecranon bursa). A left and right axillary venogram was performed and this confirmed the presence of a completely occluded left subclavian vein with extensive collateral flow (fig 2).

Haemoglobin was $131 \mathrm{~g} / \mathrm{l}$, white blood cell count $8 \cdot 7 \times 10^{9} / 1$, platelets $350 \times 10^{9} / 1$, erythrocyte sedimentation rate $2 \mathrm{~mm} / \mathrm{h}$; creatinine kinase, urea, electrolytes, liver function, chest $x$ ray, electrocardiogram, and autoantibody screen were all normal. A comprehensive clotting screen showed normal clotting times and the absence of lupus anticoagulant and anticardiolipin antibodies. Antithrombin III, protein C and $S$, and von Willebrand factor antigen were normal. An enzyme linked immunosorbent assay (ELISA) for IgG anti-endothelial cell antibodies was raised at $35 \%$ (normal $<10 \%$ ), whereas none had been detected when tested two years earlier as part of a study of patients with scleroderma and systemic lupus erythematosus (SLE). ${ }^{4}$

In view of the long interval (three months) between noticing the swollen arm and presenting in the clinic it was felt that the thrombus was probably well organised and no benefit would be gained from fibrinolytic or heparin therapy, and therefore treatment was started with oral warfarin. Further studies of her fibrinolytic potential were carried out and showed prolonged preocclusion euglobulin clot lysis time of five hours with poor response to occlusion $(1 \cdot 75$ hours). This was consistent with a low concentration of tissue plasminogen activator (1.8 $\mathrm{IU} / \mathrm{ml}$ ) and high plasminogen activator inhibitor (21.9 AU/ml). There was also reduced protein $\mathrm{C}$ activity attributable to warfarin.

When these tests were repeated one month after stopping warfarin the protein $C$ level had normalised as expected, but the same low tissue plasminogen activator $(1 \cdot 2 \mathrm{IU} / \mathrm{ml})$ and high plasminogen activator inhibitor $(21 \mathrm{AU} / \mathrm{ml})$ concentrations were found, and the preocclusion euglobulin clot lysis time was still prolonged at five hours (postocclusion two hours). Repeat assay for anti-endothelial cell IgG showed an increased level of $58 \%$ and von Willebrand factor antigen was now raised at $1.9 \mathrm{U}$ compared with $0.9 \mathrm{U}$ previously (normal $<1 \cdot 7 \mathrm{U}$ ).

She is currently treated with reducing doses of prednisone (as her myositis has been well controlled for two years) and with D-penicillamine. Any further episode of venous thrombosis would be promptly treated with parenteral 


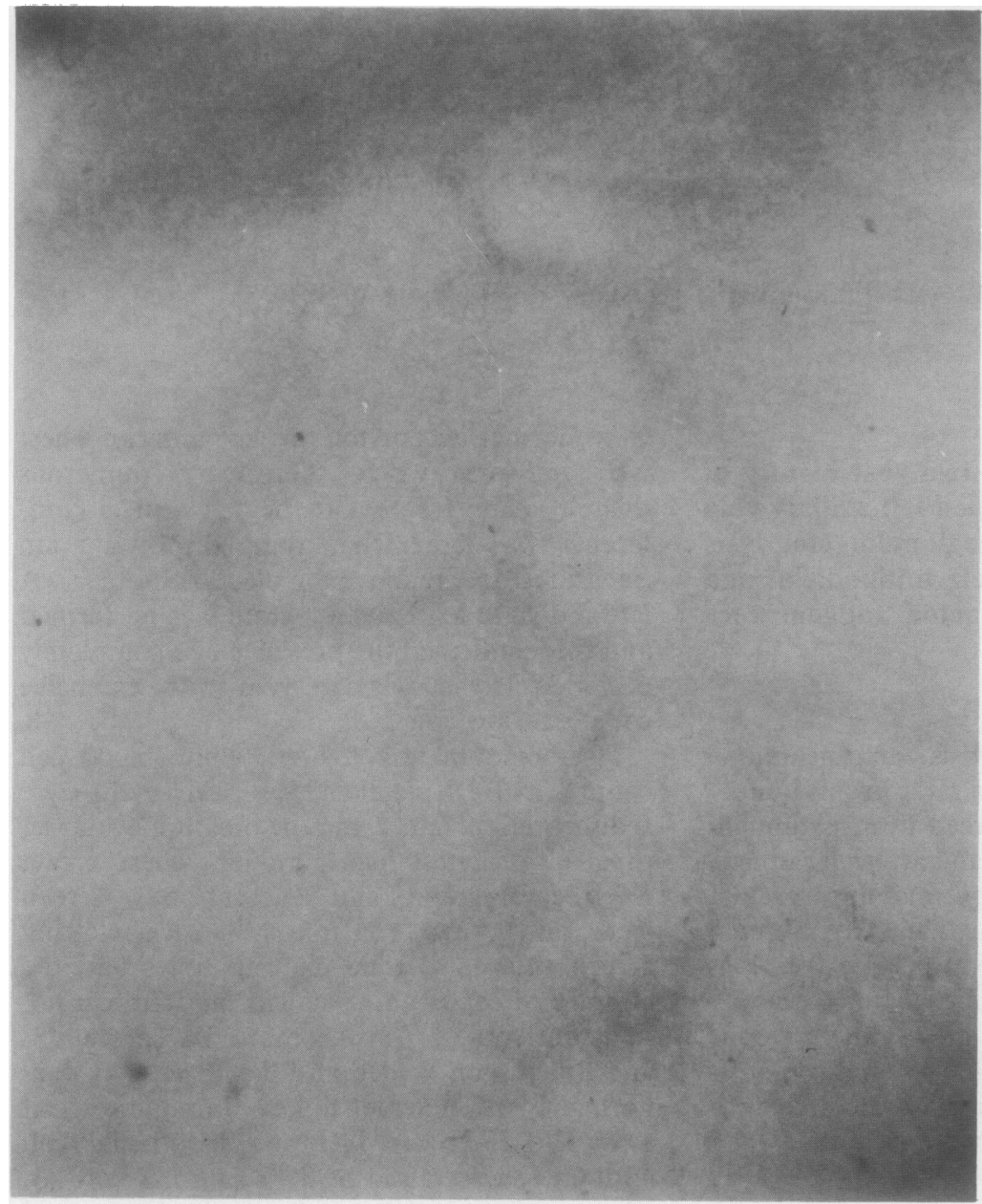

Figure 1: Left anterior chest wall showing dilated superficial veins.

tissue plasminogen activator, or eminase, and lifelong treatment with warfarin thereafter.

\section{Discussion}

Severe abnormalities of fibrinolysis have been detected in this adolescent girl with systemic sclerosis, who has had a major episode of venous thrombosis. We propose that defective production of the major physiological activator of plasminogen might be secondary to endothelial cell damage in this patient. We have shown the presence of anti-endothelial cell antibodies in her serum at the time of axillary vein throm- bosis, but not when screened previously. These antibodies have been shown in $74 \%$ of patients with SLE, not in association with either a history of thrombosis or the presence of anticardiolipin antibodies, and also in $29 / 97$ (30\%) patients with systemic sclerosis, and $28 \%$ with rheumatoid arthritis. ${ }^{4}$ They were absent in normal controls, and serial studies have not to our knowledge been performed. Whether these IgG antibodies are a pathogenic factor in the vascular damage or expressed as a consequence of endothelial cell injury is uncertain.

von Willebrand factor in the circulation is predominantly derived by secretion from endothelial cells and raised concentrations have been associated with vasculitic and connective tissue diseases, though only a proportion of patients are affected. ${ }^{356}$ von Willebrand factor antigen rose after the clinical event and was well above normal six months later, suggesting continuing endothelial damage. Increase of von Willebrand factor antigen may correlate with more extensive visceral disease, ${ }^{78}$ and if the same 'disease score' were used for scleroderma ${ }^{8}$ our patient would fit in the 'severe' group with a score of 11.

Widespread intimal proliferation affects small and medium sized arteries in scleroderma. Other factors such as reduced blood flow, increased platelet activation and adhesion, ${ }^{9}$ and activation of the coagulation cascade potentiate the risk for thrombosis. The euglobulin clot lysis time is widely used as a screening test for the balance of profibrinolytic and antifibrinolytic potential. The postvenous occlusion euglobulin clot lysis time is a test of the vascular fibrinolytic response. Measurement of the main plasminogen activator and its inhibitor gives further specific information on the fibrinolytic system. Abnormally prolonged pre- and postocclusion euglobulin clot lysis times, and depressed concentrations of tissue plasminogen activator or increased plasminogen activator inhibitor, or both, are found in about half of all patients with recurrent venous thrombosis. Impaired fibrinolytic activity, as measured by the pre- and postocclusion euglobulin clot lysis time, has been shown in systemic sclerosis, with fibrinolysis times in patients being twice that of normal controls. ${ }^{1011}$ Abnormal fibrinolysis has also been observed in women with SLE and correlates with the overall severity of disease. ${ }^{12}$

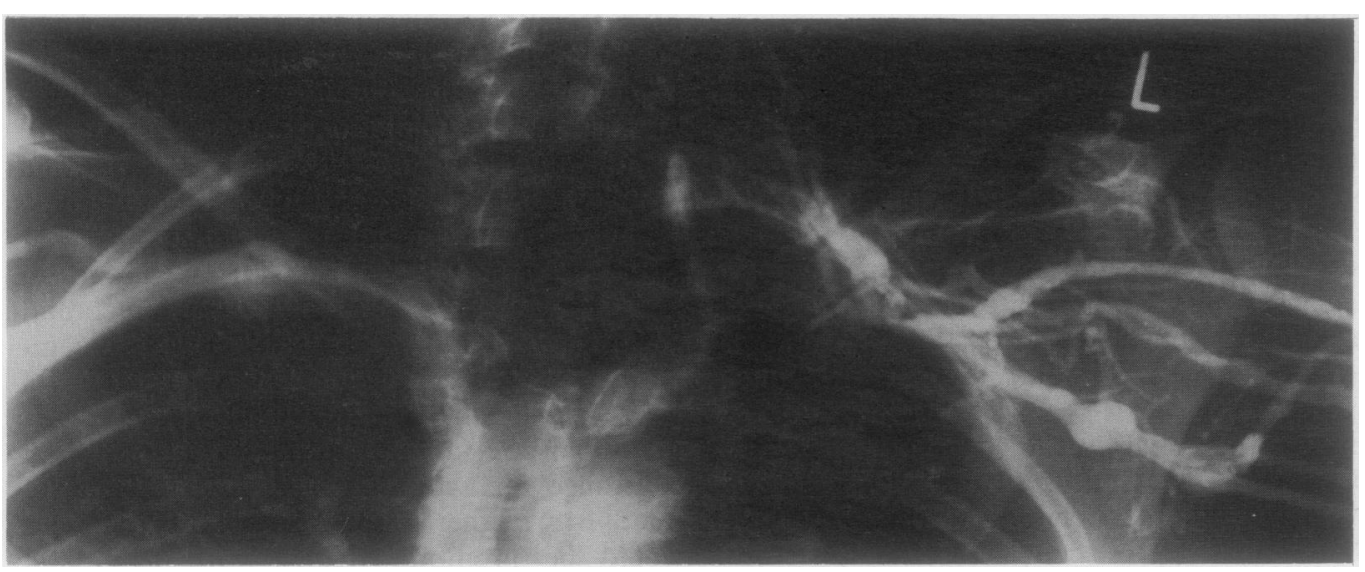

Figure 2: Bilateral venogram showing occluded left axillary and left subclavian veins with extensive dilated collaterals. 
Many different factors might operate tc produce the procoagulant environment in which there is deficient lysis of thrombi in injured veins in patients with both systemic sclerosis and SLE. ${ }^{3}$ Major vessel thrombosis is an uncommon event in systemic sclerosis and in one study only five out of 100 patients had thrombotic occlusion of major arteries. Local diminished fibrinolytic activity was shown in the affected vessels by histochemical studies, but there was no evidence for a generalised disorder of the clotting mechanism. ${ }^{13}$ It is in SLE that venous thromboses are regularly seen, ${ }^{14}$ usually in association with the lupus anticoagulant. Whereas patients with SLE have a significantly increased endothelial cell procoagulant activity by an in vitro one stage and two stage clotting assay, ${ }^{15}$ patients with systemic sclerosis have a significant decrease. This may in part explain the rarity of thrombotic events in patients with systemic sclerosis. ${ }^{15}$ Although there is mounting evidence of laboratory abnormalities, suggesting endothelial damage, a hypercoagulable state with platelet aggregation, possible microemboli, and defective fibrinolysis in systemic sclerosis, unknown factors seem to protect such patients from thrombosis.

Our patient's axillary vein thrombosis may be unrelated to systemic sclerosis, but in view of the abnormal fibrinolytic potential it is tempting to speculate that it was associated with her underlying disease. We await further reports of similar events, which would strengthen this impression.
1 Kornreich H K, Koster-King K, Bernstein B H, Singsen B H, Hanson V. Scleroderma in childhood. Arthritis Rheum 1977; 20: 343-50.

2 Singsen B H. Scleroderma in childhood. Pediatr Clin North Am 1986; 33: 1119-39.

3 Kahaleh M B, LeRoy E C. Vascular factors in the pathogenesis of systemic sclerosis. In: Jayson M I V, Black C M, genesis of systemic scierosis. In: Jayson M I V, Black C M, eds. Systemic

4 Rosenbaum J, Pottinger B E, Loizou S, et al. Measurement and characterisation of circulating anti-endothelial cell IgG in connective tissue diseases. Clin Exp Immunol 1988; 72: 450-6.

5 Nusinow S B, Federici A B, Zimmerman T S, Curd J G. Increased von Willebrand factor antigen in the plasma of patients with vasculitis. Arthritis Rheum 1984; 27 : 1405-10.

6 Gordon J L, Pottinger B E, Woo P, Rosenbaum J, Black $\mathrm{C}$ M. Plasma von Willebrand factor in connective tissue C M. Plasma von Willebrand factor in con
disease. Ann Rheum Dis 1986; 45: 491-2.

7 Lee P, Norman C S, Sukenik S, Alderdice C A. The clinical significance of coagulation abnormalities in systemic sclerosis (scleroderma). I Rheumatol 1985; 12: 514-7.

8 Greaves M, Malia R G, Milford Ward A, et al. Elevated von Willebrand factor antigen in systemic sclerosis: relationship to visceral disease. Br $\mathcal{F}$ Rheumatol 1988; 27: 281-5.

9 Kahaleh M B, Scharstein K K, LeRoy E C. Enhanced platelet adhesion to collagen in scleroderma. Effect of platelet adhesion to collagen in scleroderma. Effect of 1985; 12: 468-71.

10 Jarrett P E M, Morland M, Browse N L. Treatment of Raynaud's phenomenon by fibrinolytic enhancement. $\mathrm{Br}$ Med F 1978; ii: 523-5.

11 Holland C D, Jayson M I V. Venous blood fibrinolysis and fibrinolytic potential in primary Raynaud's phenomenon and systemic sclerosis associated Raynaud's phenomenon. In: Bster sclosic (scleroderma). New York: Gower Medical, 1985: 267-73.

12 Awada H, Barlowatz-Meimon G, Dougados M, Maisonneuve P, Sultan Y, Amor B. Fibrinolysis abnormalities in P, Sultan Y, Amor B. Fibrinolysis abnormalities in litis. F Lab Clin Med 1988; 111: 229-36.

13 Furey N L, Schmid FR, Kwaan H C, Friederici H H R. Arterial thrombosis in scleroderma. Br $\mathcal{F}$ Dermatol 1975 93: 683-93.

14 Byron M A. The clotting defect in SLE. Clin Rheum Dis 1982; 8: 137-51

15 Rustin M H A, Bull H A, Machin S J, et al. Effects of the lupus anticoagulant in patients with systemic lupus erythematosus on endothelial cell prostacyclin release and procoagulant activity. F Invest Dermatol 1987; 90: 744-8. 